\title{
ФИЗИКО-ХИМИЧЕСКИЕ СВОЙСТВА ХВОЙНОЙ НЕБЕЛЕНОЙ ЦЕЛЛЮЛОЗЫ С МОДИФИЦИРОВАННОЙ ТЕТРАХЛОРИДОМ ТИТАНА ПОВЕРХНОСТЬЮ
}

\author{
(C) Л.А. Кувиинова * С.В. Фролова, В.А. Демин \\ Институт химии Коми научного центра Уральского отделения РАН, \\ ул. Первомайская, 48, Сыктывкар, 167982, Республика Коми (Россия), \\ e-mail: fragl74@mail.ru
}

В результате воздействия растворов тетрахлорида титана в гексане на хвойную небеленую целлюлозу получены образцы в виде тонкодисперсных порошков с модифицированной поверхностью. Выявлено, что в состав агломератов, адсорбированых на поверхности образцов, входят элементы - титан и хлор. Показаны взаимосвязи физико-химических характеристик образцов от содержания на модифицированной поверхности Ti (IV).

Ключевые слова: биополимер, лигноуглеводный комплекс, хвойная небеленая целлюлоза, модифицированная поверхность, тетрахлорид титана, насыпная плотность, функциональные группы, ионообменная емкость.

Работа выполнена при финансовой поддержке программы Президиума РАН «Создание и совершенствование методов химического анализа и исследования структуры веществ и материалов» (Проект 12-П-3-1024).

\section{Введение}

Растительные биополимеры востребованы во многих отраслях промышленности (химической, пищевой, фармацевтической и др.). Источником для их получения является доступное возобновляемое сырье древесного и травянистого происхождения. Совокупность физико-химических свойств биополимеров лигнина, целлюлозы и гемицеллюлозы, образующих лигноуглеводный комплекс, позволяет на его основе получать незаменимые полуфабрикаты и продукты, востребованные на мировом рынке.

Для улучшения потребительских (эксплуатационных) свойств продуктов, получаемых на основе лигноуглеводного комплекса, а также придания им новых, не характерных ранее свойств, например, таких как устойчивость к действию плесеней и микроорганизмов, негорючесть, светостойкость, бактерицидность и других [1-8], осуществляют направленное химическое модифицирование их поверхности. Нанесение на поверхность модифицирующих покрытий, как правило, проводят путем напыления, пропитки или обработки соединениями специального состава.

Перспективными каталитическими реагентами, способными оказывать модифицирующее и деструктирующее воздействия на макромолекулы биополимеров, являются кислоты Льюиса [9]. Применение их неводных растворов позволяет изменить молекулярную массу, химический состав $[10,11]$ и физико-

Кувшинова Лариса Александровна -_младший научный сотрудник, тел.: (8212) 21-99-61, e-mail: frag174@mail.ru Фролова Светлана Валерьевна - старший научный сотрудник, кандидат химических наук, тел.: (8212) 21-99-61, e-mail: frolova-sv@chemi.komisc.ru Демин Валерий Анатольевич - главный научный сотрудник, доктор химических наук, профессор, тел.: (8212) 21-99-16, e-mail: demin-va@chemi.komisc.ru химические свойства биополимеров. Например, у целлюлозы, модифицированной растворами тетрахлорида титана в гексане относительно малых концентраций, структурные и термические характеристики, а также кислотно-основные свойства значительно отличаются от соответствующих показателей исходной целлюлозы [12-14].

\footnotetext{
* Автор, с которым следует вести переписку.
} 
Данная работа посвящена изучению некоторых физико-химических характеристик поверхности хвойной небеленой целлюлозы, обработанной растворами тетрахлорида титана для раскрытия перспективных возможностей применения модифицированных продуктов в новом качестве.

\section{Экспериментальная часть}

В качестве объекта исследования использовали продукт производства ОАО «Монди Сыктывкарский ЛПК» с техническим названием «сульфатная небеленая целлюлоза хвойных пород древесины». Характеристики объекта: средняя степень полимеризации $\left(\mathrm{C \Pi}_{\mathrm{cp}}\right)$ 900, содержание лигнинной составляющей $3,3 \%$ в модификации Комарова.

Навески хвойной небеленой целлюлозы, высушенные до постоянной массы в соответствии с методикой для определения влажности [15], заливали растворами $\mathrm{TiCl}_{4}$ (в качестве растворителя кислоты Льюиса применяли $\mathrm{C}_{6} \mathrm{H}_{14}$ ) и в атмосфере аргона подвергали кипячению в колбе, снабженной обратным холодильником. Затем содержимое колбы переносили на стеклянный фильтр, отмывали тем же растворителем от избытка реагента и в течение 60 мин подвергали дополнительному прогреву в закрытом бюксе при $100 \pm 1{ }^{\circ} \mathrm{C}$. Образцы, полученные вышеописанным способом, отличались от исходной хвойной небеленой целлюлозы сыпучестью. Для придания однородного состояния их подвергали просеиванию через сито с диаметром отверстий 0,10 мм.

Для работы использовали коммерческий $\mathrm{TiCl}_{4}$, а также $\mathrm{C}_{6} \mathrm{H}_{14}$ фирмы «Вектон» квалификации «ч». Реактивы очищали простой перегонкой [16], $\mathrm{C}_{6} \mathrm{H}_{14}$ предварительно подвергали дополнительному осушению путем кипячения в атмосфере аргона со сплавом, состоящим из металлического натрия и калия (9: 1 соответственно) в присутствии индикатора - бензофенона. Поскольку $\mathrm{TiCl}_{4}$ является легкогидролизуемым реагентом, приготовление и применение его растворов проводили также в атмосфере аргона.

Определение содержания $\mathrm{Ti}(\mathrm{IV})$ в растворах $\mathrm{TiCl}_{4}$ и в образцах проводили фотоколориметрическим методом в виде окрашенного комплекса с пероксидом водорода в кислой среде [17]. Работу выполняли на фотометре КФК-3-01. Для десорбции катионов Ti (IV) из образцов применяли раствор серной кислоты с массовой концентрацией $10 \%$.

Величину средней степени полимеризации $\left(\mathrm{CП}_{\mathrm{cp}}\right)$ расчитывали на основании результатов вискозиметрии растворов исследуемых образцов в кадоксене по уравнению, приведенному для полидисперсных целлюлоз [18]:

$$
[\eta]=7 \times 10^{-3} \times \mathrm{C}^{0,9}
$$

Микроструктуру поверхности образцов изучали с помощью энергетического спектрометра Jeol JSM6400 с энергодисперсионной приставкой для микрозондового анализа Link ISIS-200. Элементный анализ осуществляли по $\mathrm{K}_{\alpha}$-серии характеристического рентгеновского излучения атомов.

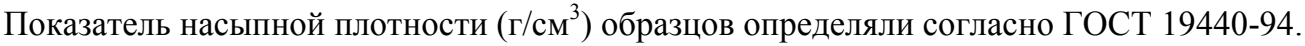

Содержание карбонильных и карбоксильных групп определяли в соответствии с известными методиками [19], основанными на конденсации гидроксиламина с карбонильными группами и хемосорбции ацетата кальция с карбоксильными группами образцов.

Величину обменной емкости $\boldsymbol{a}$ (ммоль-экв/г) определяли с помощью метода потенциометрического титрования 1\%-ной суспензий образцов [20] в растворе электролита - хлорида натрия с концентрацией 1 ммоль/дм ${ }^{3}$ в присутствии 0,1 $н$ раствора соляной кислоты. Приготовленные суспензии образцов выдерживали в течение двух часов, после чего оттитровывали. В качестве титранта использовали 0,05 н раствор гидроксида натрия. Параллельно проводили титрование фонового электролита в аналогичных условиях. Величину $а$ расчитывали по формуле:

$$
a=C \times \Delta V /\left(m \times K_{\mathrm{cyx}}\right),
$$

где $C$ - концентрация раствора титранта, моль/дм ${ }^{3} ; \Delta V$ - разность объемов раствора титранта, пошедшего на титрование суспензии исследуемого образца и фонового электролита, вычисленная при одинаковых значениях $\mathrm{pH}, \mathrm{cm}^{3} ; m$ - масса образца, г; $K_{\text {сух }}$ - коэффициент сухости образца. 


\section{Обсуждение результатов}

Воздействие растворов $\mathrm{TiCl}_{4}$ на лигноуглеводный комплекс хвойной небеленой целлюлозы, согласно полученным данным, представленным в таблице 1, приводит к накоплению в образцах катионов Ti (IV), содержание которых возрастает с увеличением концентрации применяемого раствора кислоты Льюиса и продолжительности обработки.

В первые 5 мин эксперимента происходит наиболее активное взаимодействие реагента с поверхностью лигноуглеводного комплекса. Продукты реакции отличаются повышенной массой, которая в результате обработки увеличилась на 2,7-5,3\% (по сравнению с массой исходного объекта). Взаимосвязь между этой величиной и содержанием Ti (IV) в образцах представлена на рисунке 1 в виде линейной зависимости.

Нами обнаружено, что экспериментальная масса образцов, полученных в растворах $\mathrm{TiCl}_{4}$, превышает их теоретическую массу, рассчитанную на основании результатов проведенного анализа содержания Ti (IV) в образцах. Это может быть связано с тем, что катион Ti (IV) присоединяется к биополимерам лигноуглеводного комплекса в виде $\mathrm{TiCl}_{3}$-группы [21, 22]. Накопление Ti (IV) в образцах происходит по большей части за счет ионного обмена водорода гидроксильных групп исследуемого объекта на титансодержащую группу с выделением $\mathrm{HCl}$ :

$$
\mathrm{TiCl}_{4}+\mathrm{ROH} \leftrightarrows \mathrm{ROTiCl}_{3}+\mathrm{HCl} \uparrow
$$

где $\mathrm{ROH}$ - молекула биополимера хвойной небеленой целлюлозы. В присутствии каталитических количеств молекул воды, вытесненных $\mathrm{C}_{6} \mathrm{H}_{14}$ из хвойной небеленой целлюлозы, $\mathrm{TiCl}_{3}$-группа может подвергаться дальнейшему преобразованию. Возможную межмолекулярную конденсацию титансодержащих групп, согласно литературным данным [21, 22], можно представить в следующем виде:

$$
\begin{aligned}
& \mathrm{ROTiCl}_{3}+\mathrm{H}_{2} \mathrm{O}+\mathrm{TiCl}_{4} \underset{\mathrm{HCl}}{\rightleftharpoons} \mathrm{ROTi}_{1}^{\mathrm{Cl}}-\mathrm{O}-\mathrm{TiCl}_{3} \\
& \mathrm{Cl}
\end{aligned}
$$

\begin{tabular}{|c|c|c|c|c|c|}
\hline \multirow{2}{*}{$\begin{array}{l}\text { № } \\
\text { п/ா }\end{array}$} & \multicolumn{3}{|c|}{ Условия обработки } & \multirow{2}{*}{$\begin{array}{c}\text { Содержание } \\
\operatorname{Ti}(\mathrm{IV}), \text { ммоль } / \Gamma_{\text {цел }}\end{array}$} & \multirow{2}{*}{$\begin{array}{c}\text { СП }{ }_{\text {ср }} \\
\text { целлюлозы }\end{array}$} \\
\hline & $\mathrm{C}\left(\mathrm{TiCl}_{4}\right)$, ммоль/дм ${ }^{3}$ & Содержание Ti(IV) в гексане, ммоль/ $\Gamma_{\text {цел }}$ & $\tau$, мин & & \\
\hline 1 & - & - & - & 0 & 900 \\
\hline 2 & 16,05 & 0,24 & 5 & 0,19 & 290 \\
\hline 3 & 16,05 & 0,24 & 30 & 0,20 & 290 \\
\hline 4 & 30,70 & 0,46 & 5 & 0,22 & 270 \\
\hline 5 & 34,90 & 0,52 & 15 & 0,32 & 240 \\
\hline 6 & 43,60 & 0,66 & 30 & 0,33 & 230 \\
\hline
\end{tabular}

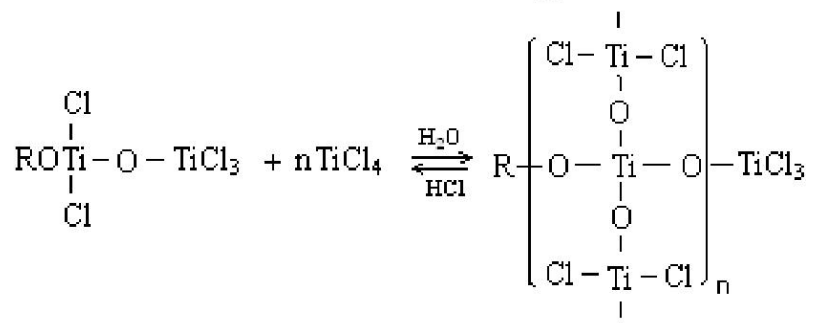

Таблица 1. Условия обработки целлюлозы и характеристика полученных образцов

Рис. 1. Взаимосвязь увеличения массы образцов и содержания в них Ti (IV)

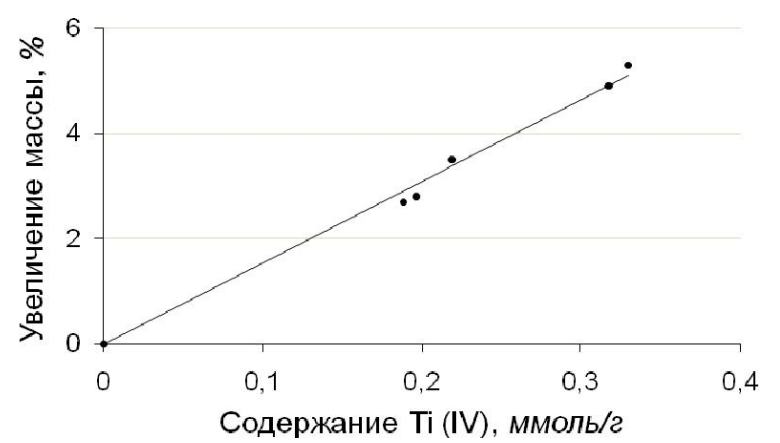


Для изучения морфологических особенностей образцов исследовали микроструктуру их поверхности, применяя сканирующую электронную микроскопию (SEM). На рисунке 2 представлены электронные микрофотографии, свидетельствующие о том, что воздействие $\mathrm{TiCl}_{4}$ на хвойную небеленую целлюлозу (2а) приводит к адсорбции на ее поверхности агломератов размером $0,02 \div 1,00$ мкм (наиболее крупные из них выделены на рисунке 2, б. Электронная микрофотография модифицированного микро- и наноразмерными частицами образца иллюстрирует шероховатую и местами разрушенную поверхность с выраженными трещинами в отличие от таковой у исходной хвойной небеленой целлюлозы (см. рис. 2).

На основании результатов микрозондового анализа образцов установлено, что в составе адсорбированных агломератов присутствуют элементы Ti и Cl. Это подтверждает, что растворы $\mathrm{TiCl}_{4}$ оказывают модифицирующее действие на хвойную небеленую целлюлозу.

Наряду с модифицирующим действием растворов $\mathrm{TiCl}_{4}$, происходит деструкция биополимерных компонентов хвойной небеленой целлюлозы, протекающая под воздействием выделившихся молекул $\mathrm{HCl}$. Так, разрыв гликозидных связей в целлюлозе приводит к разрушению ее волокон, которые превращаются в

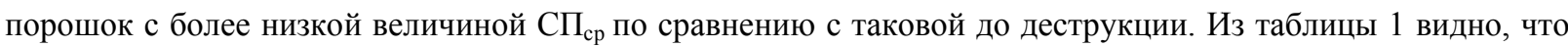
СП ср целлюлозы в образцах (в условиях проведенного эксперимента) снижается в 3-4 раза. По результатам ситового анализа все образцы имеют вид тонкодисперсного порошка с размером частиц, не превышающим 100 мкм.

Как правило, введение новых функциональных групп в любую макромолекулу приводит к изменению ее физико-химических свойств. Адсорбированные агломераты, содержащие Ti (IV), в процессе обработки хвойной небеленой целлюлозы располагаются в основном на ее поверхности оказывают влияние на изменение исследуемых характеристик образцов, таких как насыпная плотность, содержание карбонильных и карбоксильных групп.

Известно, что величина насыпной плотности зависит от формы и размера частиц, а также наличия на их поверхности шероховатостей. С увеличением содержания Ti (IV) и снижением величины СП зы в образцах происходит повышение их насыпной плотности, выявленные взаимосвязи представлены на рисунках 3 и 4.

Повышение концентрации $\mathrm{TiCl}_{4}$ в гексане и увеличение продолжительности обработки хвойной небеленой целлюлозы способствует увеличению в ней содержания карбонильных и карбоксильных групп в 2,5 и 1,6 раз соответственно, что может быть обусловлено протекающими в системе окислительными процессами [23]. На рисунке 5 в виде гистограммы представлены результаты определения функциональных групп образцов с различным содержанием в них Ti (IV).
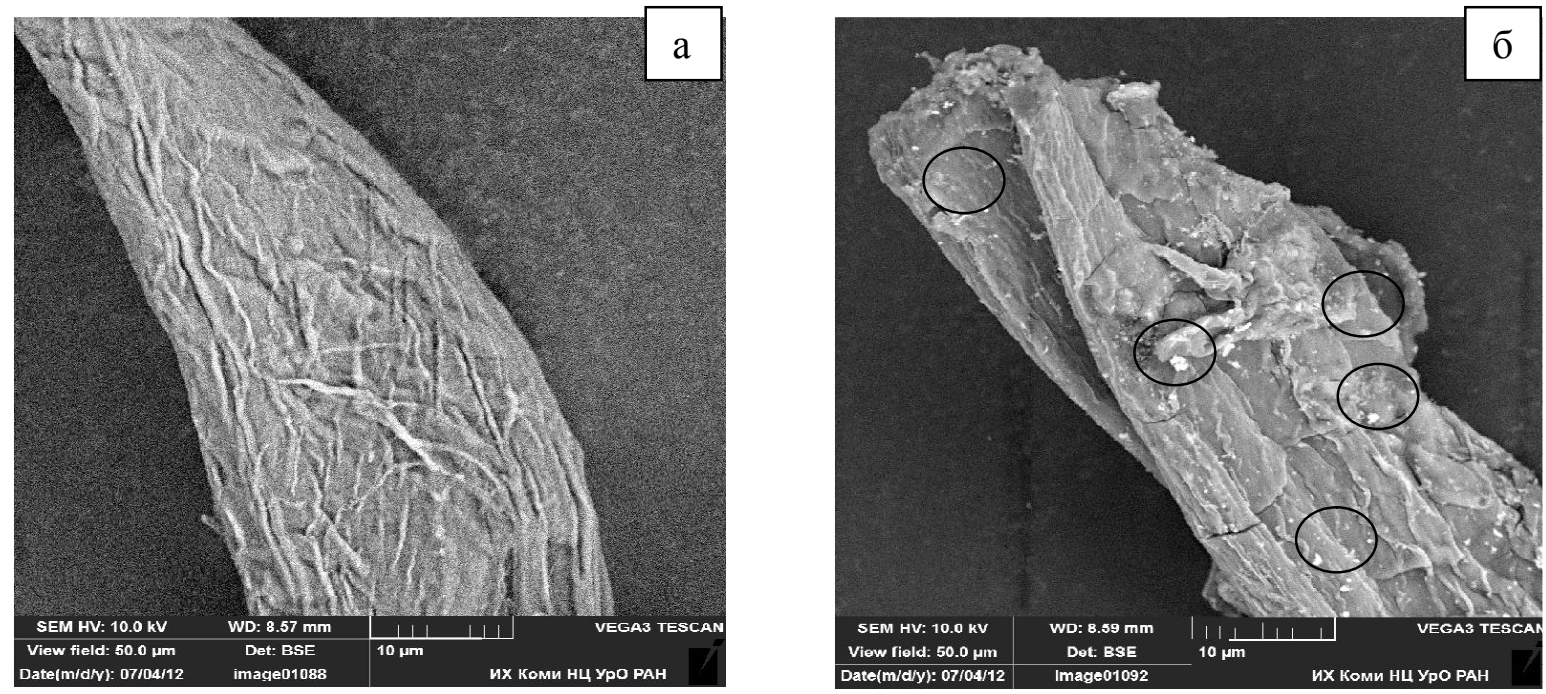

Рис. 2. Микрофотографии поверхности образцов исходной (а) и модифицированной хвойной небеленой целлюлозы (б) 


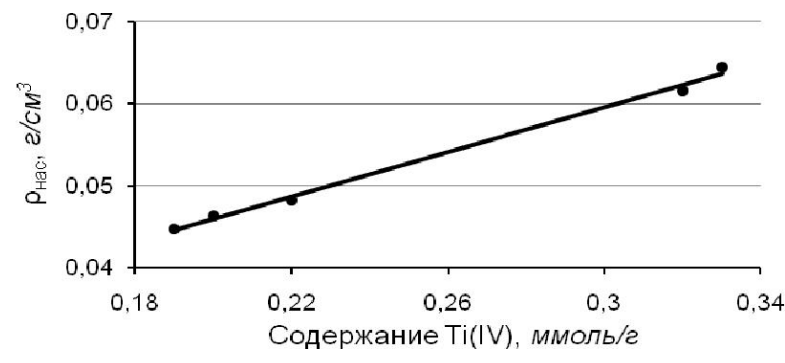

Рис. 3. Зависимость величины насыпной плотности образцов от содержания Ti (IV)

Рис. 5. Взаимосвязь содержания функциональных групп и Ti (IV) в образцах

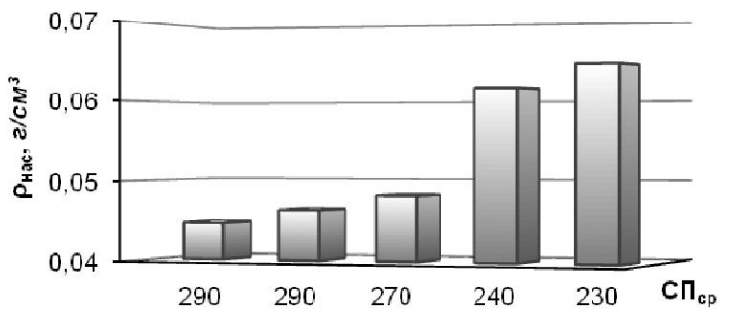

Рис. 4. Взаимосвязь насыпной плотности и величины СП

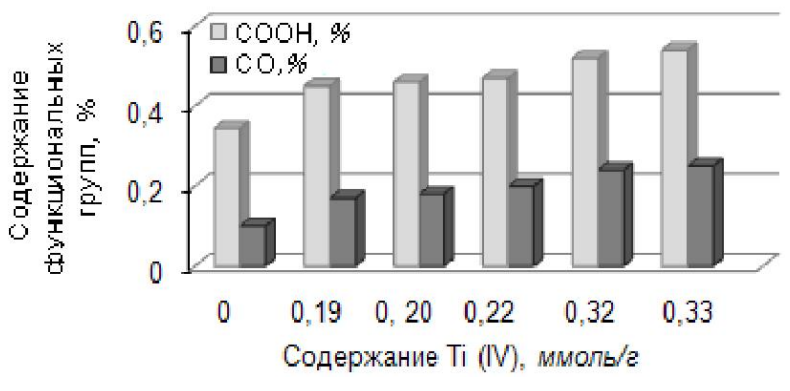

Получение высокоселективных ионитов из природных и синтетических материалов является перспективной задачей, направленной на сохранение окружающей среды. С помощью таких материалов можно решать проблемы, заключающиеся, например, в глубокой очистке промышленных и сточных вод путем избирательного извлечения из растворов ряда технически важных веществ [24]. Модифицирование поверхности природных ионитов позволяет улучшить их ионообменные свойства и тем самым направлена на повышение эффективности их действия. Для этого необходимо, чтобы мелкодисперсное сорбционноактивное вещество находилось на поверхности относительно крупнодисперсного носителя [25]. Применение способа обработки растительных биополимеров растворами $\mathrm{TiCl}_{4}$ позволяет получать продукты, удовлетворяющие вышеописанному условию.

Одной из основных характеристик любого ионита является ионообменная емкость, равная количеству ионов, обмениваемых ионитом в растворе. Как правило, эта величина в значительной степени зависит от pH среды, природы ионита, а также свойств и концентрации обменивающихся ионов [20]. На рисунке 6 представлены результаты ионообменной емкости образцов, изменяющиеся в зависимости от рН среды.

С повышением рН среды происходит постепенное увеличение ионообменной емкости образцов вследствие набухания их целлюлозной составляющей, приводящего к разрыхлению структуры образцов в щелочной среде. Это обеспечивает большую доступность ионогенных групп для раствора и соответственно для ионного обмена. При этом увеличение ионообменной емкости образцов происходит также с повышением в них содержания Ti (IV). Полученные данные хорошо описываются уравнением прямой, представленной на рисунке 7.

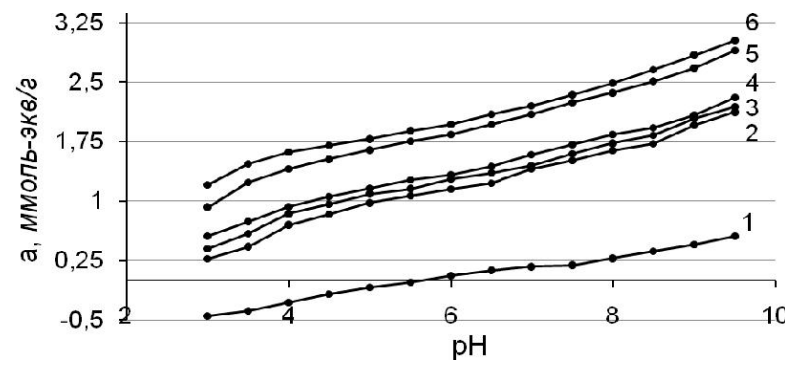

Рис. 6. Изменение ионообменной емкости образцов с различным содержанием в них Ti (IV) от рН среды: 1 - 0; $2-0,19 ; 3-0,20 ; 4-0,22$; $5-0,32 ; 6-0,33$ ммоль/г

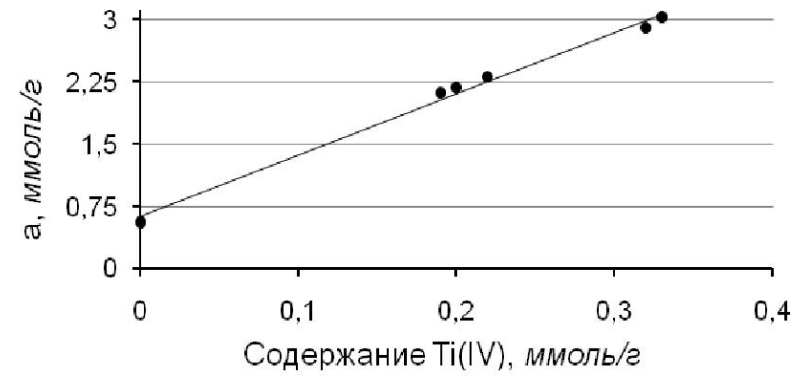

Рис. 7. Взаимосвязь обменной емкости и содержания Ti (IV) в образцах при $\mathrm{pH}=9,5$ 


\section{Заключение}

Установлено, что воздействие растворов тетрахлорида титана на хвойную небеленую целлюлозу приводит к модифицированию ее поверхности и далее к последующей деструкции ее макромолекул, в результате чего получаемые образцы приобретают вид тонкодисперсных порошков. В состав агломератов, адсорбированных на поверхности образцов, входят элементы - титан и хлор. Адсорбция титансодержащих групп поверхностью хвойной небеленой целлюлозы сопровождается увеличением ее массы. Показано, что физико-химические характеристики образцов, в частности насыпная плотность, содержание функциональных групп, ионообменная емкость зависят от содержания в них Ti (IV).

Авторы выражают благодарность старшему научному сотруднику Института химии Коми НЦ УрО РАН к.х.н. Ю.С. Матвееву за консультацию и ценные советы при подготовке растворителя к работе, младшему научному сотруднику Е.И. Истоминой за съемку микрофотографий поверхности, а также научному сотруднику Института геологии Коми НЦ УрО РАН к.г-м.н. В.Н. Филиппову за выполнение микрозондового анализа.

\section{Список литературь}

1. Азаров В.И., Буров А.В., Оболенская А.В. Химия древесины и синтетических полимеров. СПб., 1999. 628 с.

2. Телышева Г.М., Панкова Р.Е., Хрол Ю.С. Модифицирование древесины органоциклосилоксанами // Химия древесины. 1991. №1. С. 31-37.

3. Brebner K.J., Schneider M.H. Wood - polymer combinations. Boulding of alkoxysilane coupling agents to wood // Wood Sci. and Technol. 1985. Vol. 19, N1. Pp. 75-81.

4. Покровская Е.Н., Котенова И.В. Гидрофобизация древесных материалов фосфор- и кремнийорганическими соединениями // Строительные материалы. 2003. №5. С. 40-41.

5. омарова Н.Г., Новикова О.В., Чернов М.П. Силилирование лигноуглеводных материалов // Ползуновский вестник. 2006. №2. С. 136-141.

6. Чесноков Н.В., Микова Н.М., Наймушина Л.В., Кузнецов Б.Н. Свойства модифицированных медью пористых углеродных материалов, полученных пиролизом металлзамещенной целлюлозы и древесины осины // Химия растительного сырья. 2001. №4. С. 59-64.

7. Torregrosa R., Martin-Martinez J.N. Activation of lignocellulosic materials: a comparison between chemical, physical and combined activation in terms of porous texture // Fuel. 1991. Vol. 70. P. 1173.

8. Шишмаков А.Б., Паршина Е.В., Агеев М.А., Микушина Ю.В., Валова М.С., Корякова О.В., Петров Л.А. Влияние модифицирующей добавки порошковой целлюлозы на свойства ксерогеля диоксида титана в реакции окисления триметилгидрохинона // Химия растительного сырья. 2008. №3. С. 157-161.

9. Сарыбаева Р.И., Афанасьев В.А., Заиков Г.Е., Щелохова Л.С. Применение кислот Льюиса в химии углеводов // Успехи химии. 1977. Т. XLVI. Вып. 8. С. 1395-1410.

10. Патент 2478664 (РФ). Способ получения порошковой целлюлозы / С.В. Фролова, Л.А. Кувшинова, А.В. Кучин. 10.04.2013.

11. Патент 2493169 (РФ). Способ получения титансодержащих целлюлозных материалов / С.В. Фролова, Л.А. Кувшинова, А.В. Кучин. 2013.

12. Фролова С.В., Кувшинова Л.А., Алешина Л.А., Люханова И.В., Мелех Н.В. Изменение структурных характеристик сульфатной целлюлозы в зависимости от способа обработки // Химия и технология растительных веществ : материалы VI Всероссийской конференции. СПб., 2010. С. 185.

13. Фролова С.В., Кувшинова Л.А., Бугаева А.Ю., Кучин А.В. Термический анализ порошковых целлюлоз, полученных деструкцией сульфатной целлюлозы тетрахлоридом титана // Химия растительного сырья. 2011 . №2. C. $43-46$.

14. Фролова С.В., Кувшинова Л.А., Рязанов М.А., Кучин А.В. Влияние тетрахлорида титана, применяемого для получения порошковой целлюлозы, на кислотно-основные свойства ее суспензий // Химия в интересах устойчивого развития. 2012. №2. С. 243-247.

15. Оболенская А.В., Ельницкая 3.П., Леонович А.А. Лабораторные работы по химии древесины и целлюлозы. М., $1991.320 \mathrm{c}$.

16. Карякин Ю.В., Ангелов И.И. Чистые химические вещества. М., 1974. 408 с.

17. Фадеева В.И., Шеховцова Т.Н., Иванов В.И. Основы аналитической химии. М., 2001. 463 с.

18. Болотникова Л.С., Данилов С.Н., Самсонова Т.И. Метод определения вязкости и степени полимеризации целлюлозы // Журнал прикладной химии. 1966. Т. 39, №1. С. 179-180.

19. Кузнецова З.И. Методы исследования целлюлозы / под ред. В.П. Карливана. Рига, 1981. 258 с.

20. Айвазов Б.В. Практикум по химии поверхностных явлений и адсорбции : учеб. пособие для вузов. М., 1973. $208 \mathrm{c.}$

21. Суворов А.Л., Спасский С.С. Органические соединения титана // Успехи химии. 1959. Т. XXVIII. Вып. 11. C. $1267-1309$. 
22. Hider S., Marchessault R.H. Studies on alcohol-modified transition metal polymerization catalysts. II. Interaction of $\mathrm{TiCl}_{4}$ with cellulose and model compounds // J. Polymer Sci. 1965. N11. Pp. 97-105.

23. Фролова С.В. Структура и физико-химические свойства целлюлозы, деструктированной кислотами Льюиса : автореф. дис. ... канд. хим. наук. Иваново, 2009. 18 с.

24. Матерова Е.А., Белинская Ф.А., Милицина Э.Е., Скабичевский П.А. Неорганические ионообменники // Ионный обмен : сборник статей / под ред. В.А. Поздышевой. Л., 1965. С. 3-42.

25. Родинков О.В., Москвин Л.Н. Поверхностно-слойные композиционные сорбенты для экспрессного концентрирования летучих органических веществ из водных и газовых сред // Журнал аналитической химии. 2012. T. 67, №10. C. 908-916.

Поступило в редакциию 6 июня 2013 2.

Kuvshinova L.A. , Frolova S.V., Demin V.A. PHYSICOCHEMICAL PROPERTIES OF UNBLEACHED SOFTWOOD PULP WITH MODIFIED SURFACE BY TITANIUM TETRACHLORIDE

Institute of Chemistry of Komi Scientific Centre of the Ural Branch of the Russian Academy of Sciences,

Pervomaiskaya st.48, Syktyvkar, 167982 (Russia),e-mail:fragl74@mail.ru

The samples in the form of fine powders with a modified surface were obtained by treating unbleached softwood pulp solution of titanium tetrachloride in hexane. It is revealed that the composition of the agglomerates, adsorbed on the surface of samples includes elements - titanium and chlorine. Shown the correlation of physicochemical characteristics of the samples and quantity $\mathrm{Ti}$ (IV) contained on their modified surface.

Keywords: biopolymer, lignocarbohydrate complex, unbleached softwood pulp, a modified surface, titanium tetrachloride, bulk density, functional groups, ion-exchange capacity.

\footnotetext{
${ }^{*}$ Corresponding author.
} 


\section{References}

1. Azarov V.I., Burov A.V., Obolenskaya A.V. Khimiia drevesiny i sinteticheskih polimerov. [Chemistry of wood and synthetic polymers]. S-Pb, 1999, 628 p. (in Russ.).

2. Telysheva G.M., Pankova P.E., Khrol Y.S. Khimiia drevesiny, 1991, no. 1, pp. 31-37. (in Russ.).

3. Brebner K. J., Schneider M. H. Wood Sci. and Technol, 1985, vol. 19, no. 1, pp. 75-81.

4. Pokrovskaya E.N., Kotenova I.V. Building materials, 2003, no. 5, pp. 40-41. (in Russ.).

5. Komarova N.G. Novikova O.V., Chernov M.P. Polzunovskii Vestnik, 2006, no. 2, pp. 136-141. (in Russ.).

6. Chesnokov N.V., Mikova N.M., Naymushina L.V., Kuznetsov B.N. Khimiia rastitel'nogo syr'ia, 2001, no. 4, pp. 5964. (in Russ.).

7. Torregrosa R., Martin-Martinez J.N. Fuel, 1991, vol. 70, p. 1173.

8. Shishmakov A.B., Parshina E.V., Ageev M.A., Mikushina J.V., Valova M.S., Koryakova O.V., Petrov L.A. Khimiia rastitel'nogo syr'ia, 2008, no. 3, pp. 157-161. (in Russ.).

9. Sarybaeva R.I., Afanasyev V.A., Zaikov G.E., Schelohova P.S. Uspehi khimii, 1977, vol. XLVI, no. 8, pp. $1395-1410$. (in Russ.).

10. Patent 2478664 (RU). 10.04.2013. (in Russ.).

11. Patent 2493169 (RU). 2013. (in Russ.).

12. Frolova S.V., Kuvshinova L.A., Aleshina L.A., Lyuhanova I.V., Melech N.V. Khimiia I tehnologiia rastitel'nyh veshestv : materialy VI Vseros. konf. [Chemistry and technology of vegetable substances : materials of the VI allRussian conference]. St. Petersburg, Repino, 2010, p. 185. (in Russ.).

13. Frolova S.V., Kuvshinova L.A., Bugaeva A.Y., Kutchin A.V. Khimiia rastitel'nogo syr'ia, 2011, no. 2, pp. 43-46. (in Russ.).

14. Frolova S.V., Kuvshinova L.A., Ryazanov M.A., Kutchin A.V. Khimiia v interesah ustoy'chivogo razvitiia, 2012, no. 2, pp. 243-247. (in Russ.).

15. Obolenskaya A.V., Elnitskaya Z.P., Leonovich A. A. Laboratornye raboty po khimii drevesiny i tseluloze. [Laboratory works on chemistry of wood and pulp]. Moscow, 1991, 320 p. (in Russ.).

16. Karyakin J.V., Angels I.I. Chistye khimicheskie veschestva. [Clean chemical substances]. Moscow, 1974, 408 p. (in Russ.).

17. Fadeeva V.I., Shekhovtsova T.N., Ivanov V.I., and other. Osnovy analiticheskoy khimii, Moscow, 2001, 463 p. (in Russ.).

18. Bolotnikova L.S., Danilov S.N., Samsonova T.I. Jurnal prikladnoy khimii, 1966, vol. 39, no. 1, pp. 179-180. (in Russ.).

19. Kuznetsova Z.I. Research metody isledovaniia tselulozy [Methods pulp]. Riga, 1981, 258 p. (in Russ.).

20. Ayvazov B.V. Praktikum po khimii poverhnostnyh iavleniy i adsorbtsii [Workshop on chemistry of surface phenomena and adsorption]. Moscow, 1973, 208 p. (in Russ.).

21. Suvorov A.L., Spassky S.S. Uspehi khimii , 1959, vol. XXVIII, no. 11, pp. 1267-1309. (in Russ.).

22. Hider S., Marchessault R.H. J. Polymer Sci, 1965, no. 11, pp. 97-105.

23. Frolova S.V. Struktura I phizikohimicheskie svoystva tselulozy, destruktirovannoy kislotami L'uisa : dis. ... kand. khim. nauk. [Structure and physicochemical properties of cellulose, destructed by Lewis acids : Avtoref. dis. ... cand. chem. sciences]. Ivanovo, 2009, 18 p. (in Russ.).

24. Materova E.A., Belinskaya F.A., Militsina E.E., Skabichevsky P.A. Neorganicheskie ionoobmenniki. Ionny'iy obmen [Inorganic ion exchangers. Ion exchange (collection of articles)]. Leningrad, 1965, pp. 3-42. (in Russ.).

25. Rodinkov O.V., Moskvin L.N. Jurnal analiticheskoy khimii, 2012, vol. 67, no. 10, pp. 908-916. (in Russ.). 